\title{
Principals? Creative leadership practices and school effectiveness
}

\begin{abstract}
Using a quantitative approach, this study was aimed at determining teacherôs perceptions of principalsôcreative leadership practices for enhancing the effectiveness of secondary schools in Klang District in Malaysia. Premised on the Generativity Theory, the eight main core skills of challenges, broadening, capturing, manages teams, models core competencies of creativity expression, provides resources, provides work environment, and positive feedback and recognition, were examined to explore the concept of creativity in leaders. The model of High Performing School (HPS) was used to measure the School Effectiveness. A total of 250 teachers from these ten schools participated in the survey. The data was collected and analyzed. The findings revealed a moderate correlation between school principalsôcreative leadership practice and school effectiveness, followed by multiple regressionsô analysis indicated creative leadership practices dimension; Encourage Capturing received the strongest weight in the prediction. This study offers a dynamic perspective for school principals to practice creative leadership as the key factor for transforming school into an effective school.
\end{abstract}

Keyword: Creative leadership; Generativity Theory; High performing school; School effectiveness 